\title{
Erratum to: Mig6 haploinsufficiency protects mice against streptozotocin-induced diabetes
}

\author{
Yi-Chun Chen • E. Scott Colvin • Katherine E. Griffin • \\ Bernhard F. Maier • Patrick T. Fueger
}

Published online: 22 August 2014

(C) Springer-Verlag Berlin Heidelberg 2014

\section{Erratum to: Diabetologia}

DOI 10.1007/s00125-014-3311-z

Unfortunately, incorrect units of time were used in Fig. 3. The correct figure and amended legend are given here.

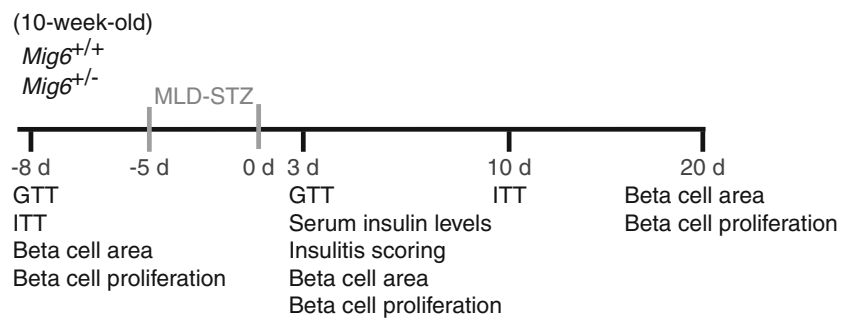

Fig. 3 Schematic representation of the experimental timeline; d, days

The online version of the original article can be found at http:// dx.doi.org/10.1007/s00125-014-3311-z.

\section{Y.-C. Chen · P. T. Fueger}

Department of Cellular \& Integrative Physiology, Indiana University

School of Medicine, Indianapolis, IN 46202, USA

E. S. Colvin • K. E. Griffin • B. F. Maier • P. T. Fueger $(\bowtie)$

Herman B. Wells Center for Pediatric Research, Indiana University

School of Medicine, 635 Barnhill Drive, MS 2031, Indianapolis,

IN 46202, USA

e-mail: pfueger@iu.edu

E. S. Colvin · K. E. Griffin • B. F. Maier • P. T. Fueger

Department of Pediatrics, Indiana University School of Medicine,

Indianapolis, IN 46202, USA 